\title{
Influence of Temperature and Wetness Duration on Conidia and Appressoria of Colletotrichum acutatum on Symptomless Strawberry Leaves
}

\author{
L. F. S. Leandro, M. L. Gleason, F. W. Nutter, Jr., S. N. Wegulo, and P. M. Dixon
}

First, second, third, and fourth authors: Department of Plant Pathology; and fifth author: Department of Statistics, Iowa State University, Ames 50011.

Accepted for publication 6 November 2002.

\begin{abstract}
Leandro, L. F. S., Gleason, M. L., Nutter, F. W., Jr., Wegulo, S. N., and Dixon, P. M. 2003. Influence of temperature and wetness duration on conidia and appressoria of Colletotrichum acutatum on symptomless strawberry leaves. Phytopathology 93:513-520.

Strawberry leaves (cv. Tristar) inoculated with Colletotrichum acutatum conidia were incubated at $10,15,20,25,30$, and $35^{\circ} \mathrm{C}$ under continuous wetness, and at $25^{\circ} \mathrm{C}$ under six intermittent wetness regimes. The number of conidia and appressoria was quantified on excised leaf disks. In order to assess pathogen survival, inoculated leaves were frozen and incubated to induce acervular development. Germination, secondary conidiation, and appressorial development were significantly $(P \leq 0.05)$ affected by temperature and wetness treatments. Under continuous wet-

ment ranged from 17.6 to $26.5^{\circ} \mathrm{C}$. Secondary conidiation showed an optimum temperature range of 21.3 to $32.7^{\circ} \mathrm{C}$ and was most abundant between 12 and $36 \mathrm{~h}$ after inoculation. Conidial germination, appressorial production, and secondary conidiation were favored by increasing wetness duration and more than $4 \mathrm{~h}$ of wetness were required for secondary conidiation. In a greenhouse, $C$. acutatum survived up to 8 weeks on leaves. The number of acervuli formed on leaves after freezing and incubation was closely $\left(r^{2} \geq 0.95\right)$ related to appressorial populations prior to this treatment and was greatest following periods of continuous wetness. Production of secondary conidia and appressoria of $C$. acutatum on symptomless strawberry leaves under a range of environmental conditions suggests that these processes also occur under field conditions and contribute to inoculum availability during the growing season.
\end{abstract} ness, the optimum temperature range for conidial germination was 23.0 to $27.7^{\circ} \mathrm{C}$, whereas the optimum temperature for appressorial develop-
Additional keywords: anthracnose fruit rot, phyllosphere.
Anthracnose fruit rot, caused by Colletotrichum acutatum J.H. Simmonds, presents a major challenge for strawberry production worldwide $(4,16-18,36)$. Under favorable environmental conditions, this disease can devastate entire production fields $(14,17)$ and cause significant losses in the nursery industry $(7,8,37)$. Fruit rot is the most important symptom caused by $C$. acutatum on strawberries, but lesions can develop on all other plant parts (13, 17,36). Stolon lesions reduce runner plant production, and crown rots kill plants in nurseries and production fields after transplanting $(17,36,37)$. C. acutatum has also been implicated in recent disease outbreaks in greenhouse strawberry production (15).

Long-distance dissemination of the pathogen occurs on contaminated propagation material $(7,8,13,14,22,36)$. Transplants may harbor inoculum in lesions $(17,24)$, in infested soil attached to roots (7), or as conidia or quiescent infections on symptomless foliage $(10,12,19,33)$. After sporulation occurs on lesions or senescent plant material, dissemination of the fungus occurs mainly by splash dispersal (43), but may also occur through handling of plants (31), especially during harvest (22).

The epidemiology of $C$. acutatum on strawberry has been well characterized with regard to splash dispersal of conidia (25-27, $42,43)$, infection and sporulation on fruit $(18,39)$, and survival in plant debris and soil $(7,8,40)$. Little is known, however, about the behavior of $C$. acutatum on symptomless plants prior to the onset of an epidemic. C. acutatum conidia can germinate, form appressoria, and produce secondary conidia on symptomless strawberry

Corresponding author: M. L. Gleason; E-mail address: mgleason@iastate.edu

Publication no. P-2003-0220-02R

(C) 2003 The American Phytopathological Society leaves when incubated at $26^{\circ} \mathrm{C}$ under continuous wetness (19). The fungus was also shown to survive under greenhouse conditions on asymptomatic leaves of several plant species (12). These studies suggested that symptomless foliage might play an important role in the anthracnose disease cycle both as a refuge for fungal survival and a source of inoculum for fruit and flower infections $(12,19,33)$. Temperature and wetness have been reported to affect mycelial growth $(1,7,11,21,37,39)$, germination and sporulation of C. acutatum on agar (11), and infection and sporulation on fruit $(18,39)$, but similar work has not been done on strawberry foliage. Furthermore, production of secondary conidia was not addressed in these earlier studies.

In order to develop more effective management tactics, there is a need to understand the behavior of $C$. acutatum on strawberry leaves under a range of environmental conditions. The objectives of this study were to (i) determine the effects of temperature and intermittent wetness on germination and secondary conidiation of C. acutatum on strawberry leaves, and (ii) assess the potential for C. acutatum to survive on symptomless strawberry leaves. A preliminary report has been published (20).

\section{MATERIALS AND METHODS}

Plant production and maintenance. Day-neutral strawberry crowns (cv. Tristar) were planted in 15 -cm-diameter plastic pots containing a 1:2:1 mixture of peat, perlite, and soil, and grown in a greenhouse at $25 \pm 10^{\circ} \mathrm{C}$ with a 16-h photoperiod. The plants were drip-irrigated and fertilized with a solution of a 21-5-20 fertilizer (Miracle Gro Excel, 400 ppm N) as needed. For each experiment, newly emerged leaves were tagged 7 to 14 days before inoculation to ensure uniformity of leaf age. 
Inoculum production. Isolate $\mathrm{HF}-\mathrm{ac}-98$ of $C$. acutatum was obtained from an infected strawberry fruit collected at the Iowa State University Horticulture Research Farm near Gilbert, IA, and transferred to silica gel for long-term storage. All cultures used for inoculum preparation were started by depositing infested silica gel crystals on potato dextrose agar (PDA) plates and culturing at $25^{\circ} \mathrm{C}$ in darkness until conidia developed. Conidia collected from PDA cultures were spread onto strawberry fruit agar (SFA) (19) and incubated for 7 days at $25^{\circ} \mathrm{C}$ in darkness. Conidial suspensions used for inoculations were prepared by flooding each SFA culture plate with $9 \mathrm{ml}$ of sterile deionized water (SDW), scraping with a rubber policeman to dislodge conidia, filtering through two layers of cheesecloth into a flask, and adjusting the concentration to $5 \times 10^{5}$ conidia $\mathrm{ml}^{-1}$.

Temperature experiments. Tagged strawberry leaves were excised at the petiole base and placed in moist chambers $(24 \times$
$34 \times 6-\mathrm{cm}$ plastic boxes containing $500 \mathrm{ml}$ of SDW). Leaves were suspended above the water on a wire mesh and the excised ends of the petioles were inserted through the mesh into the water. For inoculation, the wire mesh was removed from each box and the leaves were sprayed with a conidial suspension with an atomizer (DeVilbiss Air Compressor, 571 Series, Somerset, PA). Approximately $5 \mathrm{ml}$ of conidial suspension was sprayed over a $20-\times 30-\mathrm{cm}$ area, resulting in an average application of 40 conidia $\mathrm{mm}^{-2}$ of leaf area. The leaves and wire mesh were returned to the boxes, which were then sealed in plastic bags to maintain approximately $100 \%$ relative humidity and incubated at 10,15 , $20,25,30$, or $35^{\circ} \mathrm{C}\left( \pm 1^{\circ} \mathrm{C}\right)$ in darkness. Temperature in the incubators (Model 6; Thelco, Chicago, IL / Model I37-L; Percival, Perry, IA) was monitored and recorded every $15 \mathrm{~min}$ using WatchDog Data Loggers (Model 150; Spectrum Technologies, Plainfield, IL).

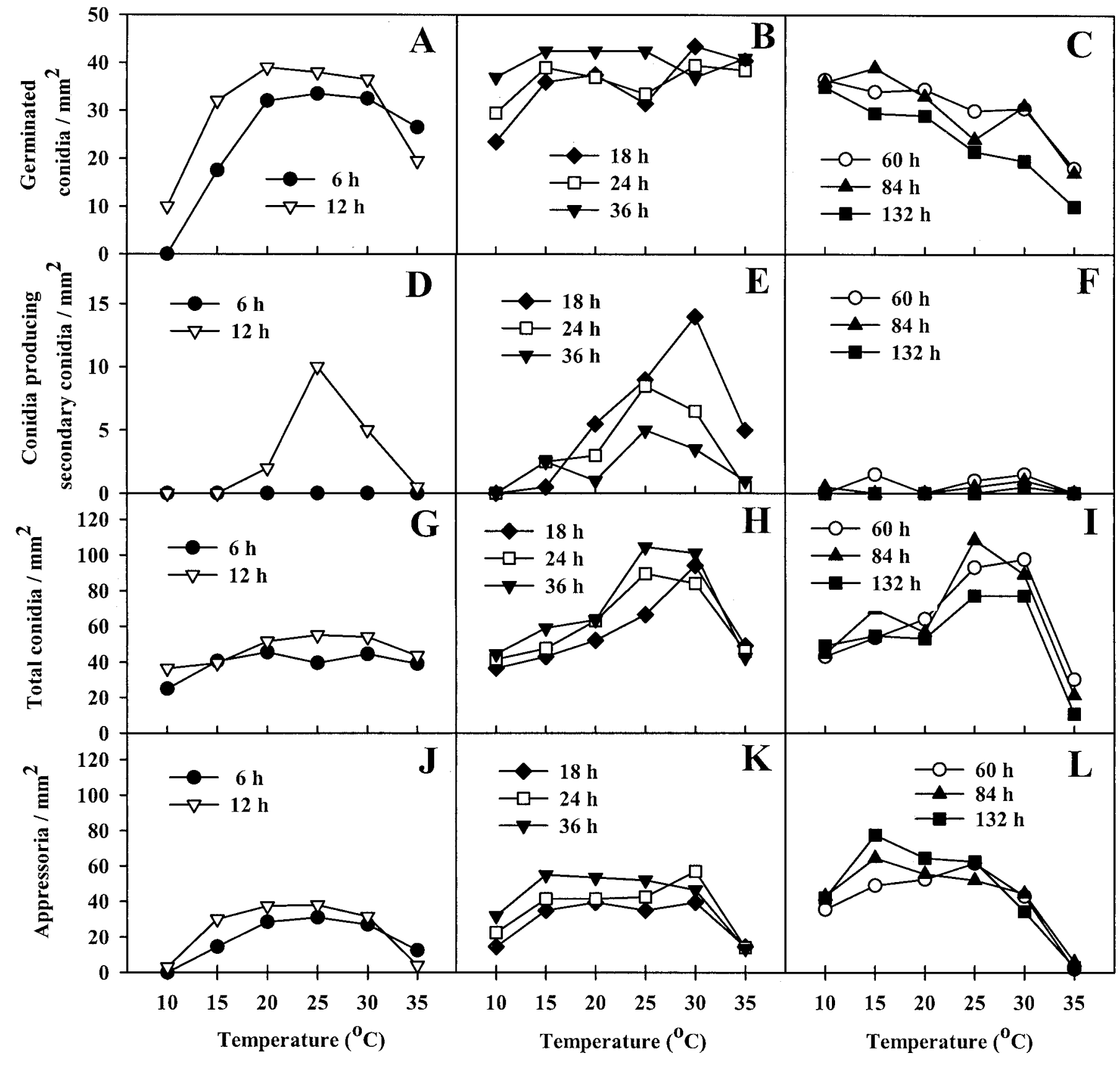

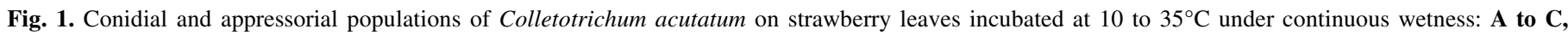

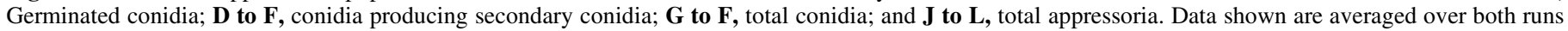
of the experiment. 
Four leaves were sampled arbitrarily from each incubator at 6 , $12,18,24,36,60,84$, and $132 \mathrm{~h}$ after inoculation. Two leaf disks were excised from each leaf, one on either side of the central vein of the middle leaflet, with a 1-cm-diameter cork borer. The disks were mounted on a drop of Hoyer's medium (6), stained with a drop of $0.1 \%$ aniline blue in lactophenol, covered with a glass coverslip, and observed under a light microscope. The total number of germinated and ungerminated conidia was counted in each of 16 microscope fields $(\times 400)$ per leaf disk. A conidium was considered germinated when it had formed either a germ tube at least as long as its width, an appressorium (a globose, septum-delimited structures formed on germ tubes or sessile to conidia), or a conidial phialide. Unmelanized and melanized appressoria were also counted. The number of conidia with a secondary conidium still attached to a conidial or hyphal phialide was quantified to estimate secondary conidiation (19). The number of total conidia (ungerminated + germinated) and total appressoria (unmelanized + melanized) was calculated. Data were expressed on an area basis (square millimeter) by dividing the total number of conidia or appressoria in each leaf disk by the area of 16 microscope fields observed per disk. Eight disks were counted at each sampling time (two disks $\times$ four leaves per sampling time), and the experiment was repeated once.

Intermittent wetness experiments. Germination and conidiation of $C$. acutatum was further investigated on the leaf surface of intact strawberry plants incubated at $25 \pm 2{ }^{\circ} \mathrm{C}$ under intermittent wetness. In order to establish six wet/dry treatment regimes, plants were alternated between dew chambers (Model I60DL; Percival) for the wet periods and a growth chamber (Model PGW36; Conviron, Winnipeg, Canada) for the dry periods. Treatments were defined by the ratio of dry to wet hours per day as follows: $0 / 24,4 / 20,8 / 16,12 / 12,16 / 8$, and 24/0. The 24-h cycles were repeated for 7 days. All plants were watered daily at the start of each cycle and kept under a 12-h dark/12-h light regime.

Ten plants arbitrarily assigned to each treatment were distributed within dew chambers and growth chambers according to a split-plot design with two blocks, using day of sampling as the whole-plot treatment and wet/dry regime as the sub-plot treatment. Each plant was spray-inoculated with a conidial suspension, using an atomizer as described previously, until all leaves were thoroughly covered with inoculum but no runoff had occurred. Following inoculation, plants were placed in dew chambers to start the wet incubation period, with the exception of plants in the continuous dry treatment, which were dried with fans for 10 to 15 min until no free water was observed on the leaves, then placed in the growth chamber. At the end of each wet period, plants were removed from the dew chamber, dried with fans (15 to $30 \mathrm{~min}$ ), and placed in the growth chamber for the remaining dry period. Initial conidial populations on the leaves were estimated using an additional set of eight plants that were inoculated, dried, and sampled immediately after inoculation (time zero assessment). Two tagged leaves from each of two plants per treatment were sampled at the end of the 24-h cycle on days 1,2,3,5, and 7 after inoculation. Two leaf disks excised from the middle leaflet of each leaf (a total of eight disks per treatment per sampling time) were prepared for microscopic observation, and conidial and appressorial numbers were quantified as described previously. The experiment was repeated once.

Survival experiments. Survival of $C$. acutatum on symptomless leaves was investigated using leaves remaining on inoculated plants that had been exposed to the wet/dry treatment regimes in the intermittent wetness experiment. At the end of the 7-day

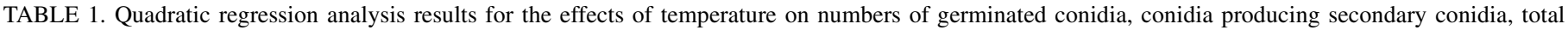
conidia, and appressoria on the surface of strawberry leaves inoculated with Colletotrichum acutatum and incubated under continuous wetness ${ }^{z}$

\begin{tabular}{|c|c|c|c|c|c|c|c|c|}
\hline Count & $\begin{array}{l}\text { Incubation } \\
\text { period }(\mathrm{h})\end{array}$ & $y$ intercept & Linear slope & $\begin{array}{l}\text { Quadratic } \\
\text { slope }\end{array}$ & $R^{2}$ & $\begin{array}{l}P \text { value for } \\
\text { lack of fit }\end{array}$ & $\begin{array}{c}\text { Temperature } \\
\text { optimum }\left({ }^{\circ} \mathrm{C}\right)\end{array}$ & $\begin{array}{c}\text { SE for temperature } \\
\text { optimum }\end{array}$ \\
\hline \multirow[t]{8}{*}{ Germinated conidia } & 6 & -54.9 & 6.79 & -0.13 & 0.91 & 0.88 & 26.5 & 0.9 \\
\hline & 12 & -57.6 & 8.37 & -0.18 & 0.81 & 0.80 & 23.8 & 0.7 \\
\hline & 18 & - & - & - & - & - & - & - \\
\hline & 24 & - & - & - & - & - & - & - \\
\hline & 36 & - & - & - & - & - & - & - \\
\hline & 60 & - & - & - & - & - & - & - \\
\hline & 84 & - & - & - & - & - & - & - \\
\hline & 132 & - & - & - & - & - & - & - \\
\hline \multirow{9}{*}{$\begin{array}{l}\text { Conidia producing } \\
\text { secondary conidia }\end{array}$} & & & & & & & & \\
\hline & 6 & - & - & - & - & - & - & - \\
\hline & 12 & -16.0 & 1.77 & -0.04 & 0.50 & $0.019 *$ & 24.5 & 1.8 \\
\hline & 18 & -17.9 & 1.92 & -0.03 & 0.61 & 0.29 & 28.3 & 4.4 \\
\hline & 24 & -15.3 & 1.80 & -0.04 & 0.66 & $0.005^{*}$ & 24.0 & 1.1 \\
\hline & 36 & -7.14 & 0.87 & -0.02 & 0.23 & 0.69 & 24.4 & 3.1 \\
\hline & 60 & -1.62 & 0.23 & -0.005 & 0.13 & 0.18 & 23.1 & 3.3 \\
\hline & 84 & - & - & - & - & - & - & - \\
\hline & 132 & - & - & - & - & - & - & - \\
\hline \multirow[t]{8}{*}{ Total conidia } & 6 & -3.27 & 3.81 & -0.08 & 0.81 & 0.055 & 25.4 & 0.4 \\
\hline & 12 & -0.86 & 4.31 & -0.09 & 0.71 & 0.61 & 25.2 & 0.4 \\
\hline & 18 & -29.5 & 7.21 & -0.13 & 0.48 & $0.041 *$ & 27.5 & 1.1 \\
\hline & 24 & -52.6 & 10.7 & -0.22 & 0.61 & 0.13 & 24.6 & 1.5 \\
\hline & 36 & -73.9 & 13.7 & -0.28 & 0.60 & 0.10 & 24.1 & 1.8 \\
\hline & 60 & -77.0 & 13.9 & -0.30 & 0.64 & 0.10 & 23.4 & 1.8 \\
\hline & 84 & -86.2 & 15.7 & -0.35 & 0.55 & 0.097 & 22.4 & 1.3 \\
\hline & 132 & -43.0 & 10.8 & -0.25 & 0.57 & 0.15 & 21.4 & 2.0 \\
\hline \multirow[t]{8}{*}{ Appressoria } & 6 & -61.4 & 7.56 & -0.16 & 0.94 & 0.66 & 24.4 & 1.3 \\
\hline & 12 & -78.9 & 10.6 & -0.24 & 0.91 & 0.71 & 22.6 & 1.6 \\
\hline & 18 & -41.9 & 7.36 & -0.16 & 0.61 & 0.70 & 22.6 & 3.9 \\
\hline & 24 & -42.1 & 8.13 & -0.18 & 0.49 & 0.37 & 22.6 & 1.4 \\
\hline & 36 & -34.2 & 8.83 & -0.21 & 0.80 & 0.67 & 20.9 & 1.5 \\
\hline & 60 & -48.3 & 10.6 & -0.26 & 0.84 & 0.49 & 20.5 & 1.4 \\
\hline & 84 & -14.8 & 8.03 & -0.21 & 0.81 & 0.62 & 19.1 & 1.3 \\
\hline & 132 & -33.0 & 10.8 & -0.28 & 0.88 & 0.47 & 19.2 & 1.6 \\
\hline
\end{tabular}

$\mathrm{z} *$ indicates significant lack of fit at $P=0.05$. - indicates linear regression results are not reported if standard error (SE) for temperature optimum $>5$. 
incubation period, plants were dried with fans and all inoculated leaves were tagged to distinguish them from newly emerging, noninoculated leaves. The plants were then transferred to a greenhouse bench where they were maintained at $30 \pm 10^{\circ} \mathrm{C}$ and dripirrigated to prevent free moisture on leaves. In both runs of the experiment, one tagged leaf was sampled from each of four plants per treatment at 1,2, 4, 6, and 8 weeks after transfer to the greenhouse bench. In the second run, leaves were also sampled on the day of transfer from the chambers to the greenhouse bench (week 0 ). Sampled leaves were bagged and frozen overnight in order to kill leaf tissue and incubated for 7 days at $25^{\circ} \mathrm{C}$ and $100 \%$ relative humidity in moist chambers, as described previously, to induce acervular development by $C$. acutatum (28). The total number of acervuli on the middle leaflet of each leaf, counted with a dissecting microscope $(\times 10)$, was divided by the leaflet area, measured with a leaf area meter (Model 3100; Li-Cor, Lincoln, NE), to estimate the number of acervuli per square centimeter.

Data analysis. Quadratic regression analysis was performed on data from the temperature experiment using the general linear models (GLM) procedure of SAS (SAS Institute, Cary, NC). Temperature optima and confidence intervals for each type of measurement were estimated based on Fieller's theorem. Linear regression analysis was performed using the GLM procedure on data for the intermittent wetness experiment, excluding data for the $0 \mathrm{~h}$ wetness treatment. Survival on leaves was analyzed separately for each run of the experiment according to a randomized complete block design with two replications. Area under the curve (AUC) values were calculated and compared using Duncan's multiple range test. Nonlinear regression analysis was performed using SigmaPlot 2000 (SPSS, Chicago, IL) to determine the relationship between the number of acervuli formed on leaves after freezing and the number of appressoria on leaves at week 0 of the survival experiment (i.e., day 7 of intermittent wetness experiment). Statistical significance of all analyses was expressed at the $P \leq 0.05$ threshold.

\section{RESULTS}

Temperature experiments. $C$. acutatum conidia germinated, formed appressoria, and produced secondary conidia at all temperatures studied (Fig. 1). The timing and magnitude of these processes were, however, significantly affected by temperature. An optimum temperature range of 23.0 to $27.7^{\circ} \mathrm{C}$ was observed for conidial germination within $12 \mathrm{~h}$ after inoculation (Table 1; Fig. 1A), but by $18 \mathrm{~h}$ the number of germinated conidia was similar among temperatures (Fig. 1B). After $60 \mathrm{~h}$, the number of germinated conidia tended to decrease with increasing temperature, probably due to cell lysis. Conidia appeared unusually swollen and highly vacuolated at $35^{\circ} \mathrm{C}$ starting $12 \mathrm{~h}$ after inoculation.

Temperature significantly influenced production of secondary conidia on the surface of symptomless leaves, determined by the

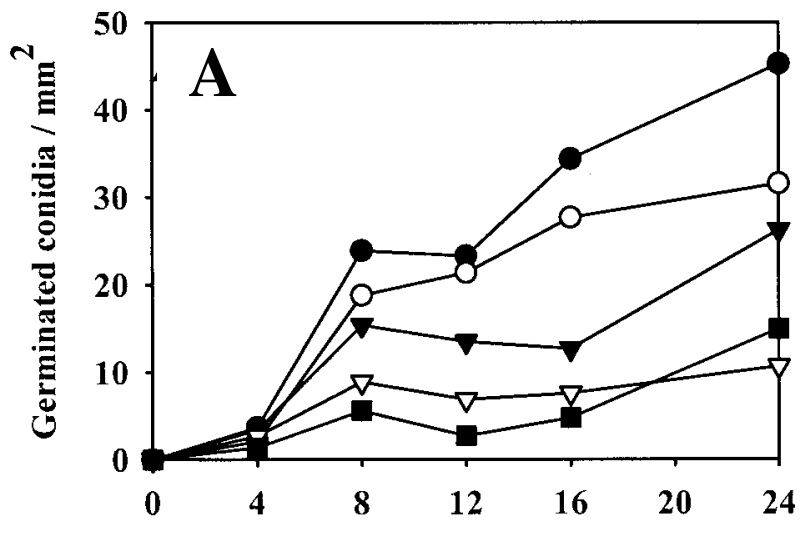

Wetness duration (h/day)

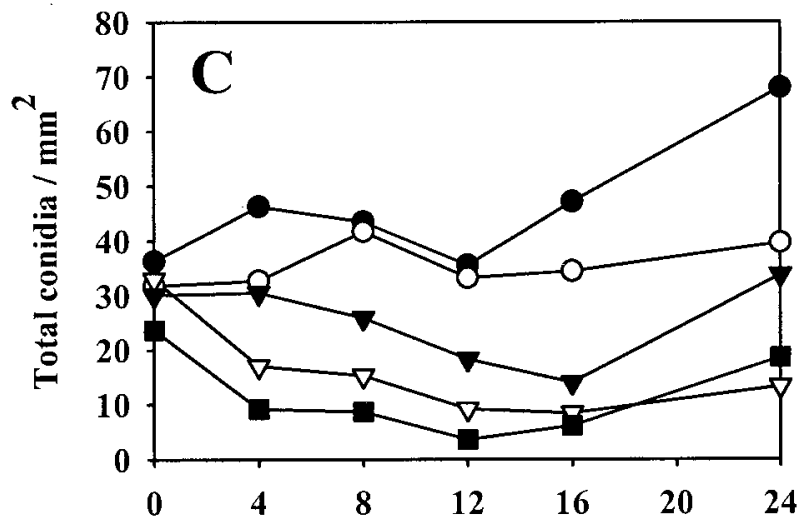

Wetness duration (h / day)

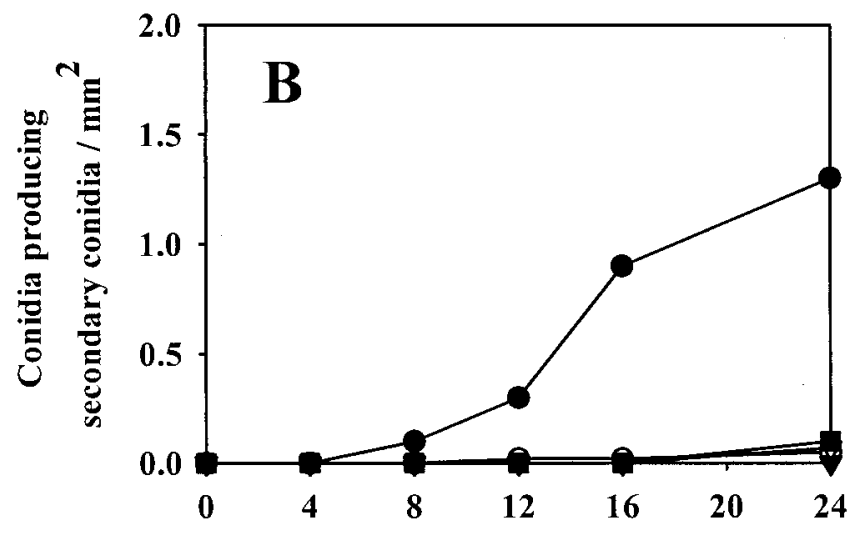

Wetness duration ( $h$ / day)

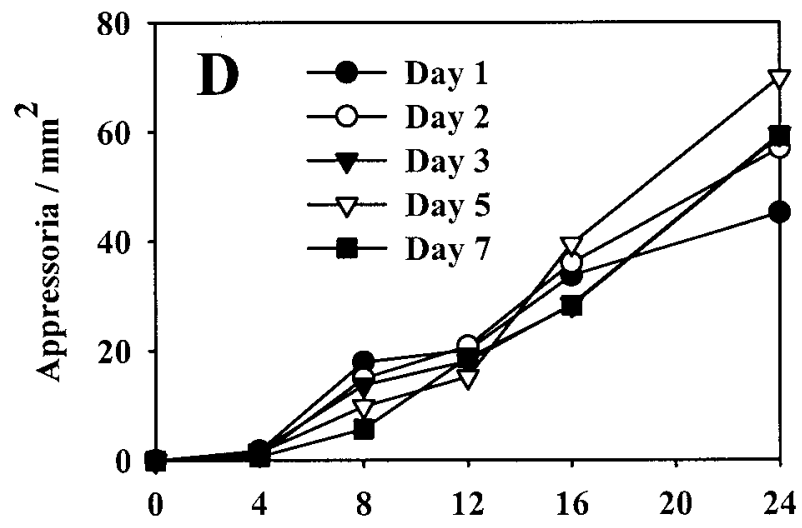

Wetness duration (h / day)

Fig. 2. Conidial and appressorial populations of Colletotrichum acutatum on strawberry leaves incubated at $25^{\circ} \mathrm{C}$ and different wet/dry treatment regimes: A, Germinated conidia; B, conidia producing secondary conidia; $\mathbf{C}$, total conidia, and $\mathbf{D}$, total appressoria. Data shown are averaged over both runs of the experiment. 
number of conidia observed with a secondary conidium attached to a conidial or hyphal phialide (19). The optimum temperature for secondary conidiation ranged from approximately 21.3 to $32.7^{\circ} \mathrm{C}$ between 12 and $36 \mathrm{~h}$ after inoculation (Table 1). Secondary conidiation was rare at $10^{\circ} \mathrm{C}$ and at sampling times of $>36 \mathrm{~h}$ after inoculation (Fig. 1D to F). Production of secondary conidia increased the total number of conidia on the surface of symptomless leaves, particularly at 25 and $30^{\circ} \mathrm{C}$, at which total conidia more than doubled during the experiment (Fig. 1G to I). Although the number of germinated conidia began to decrease by $60 \mathrm{~h}$, this decrease was counterbalanced by high numbers of ungerminated conidia produced by secondary conidiation at these temperatures.

Production of appressoria was favored by cooler temperatures than conidial germination and secondary conidiation (Fig. 1J to L). The optimum for appressorial production ranged from 17.6 to $26.5^{\circ} \mathrm{C}$ and decreased with time after inoculation (Table 1). For example, although appressorial production was faster at 23 to $26^{\circ} \mathrm{C} 6 \mathrm{~h}$ after inoculation, the largest number of appressoria was observed at 17.6 to $20.8^{\circ} \mathrm{C} 132 \mathrm{~h}$ after inoculation. Overall, the least favorable temperature for appressorial production was $35^{\circ} \mathrm{C}$ (Fig. 1J to L).

Intermittent wetness. Conidial germination, secondary conidiation, and appressorial development were significantly affected by wet/dry treatment regime at $25^{\circ} \mathrm{C}$ (Fig. 2). Conidial germination increased with increasing daily period of wetness duration, indicated by the positive slopes of the regression (Table 2), and never occurred in the continuously dry treatment (Fig. 2A). The number of germinated conidia was largest 1 day after inoculation in all treatments with $\geq 8 \mathrm{~h}$ wetness per day, and then decreased over time in all treatments.

Production of secondary conidia occurred mainly within 1 day after inoculation and was rare at later sampling times (Fig. 2B). Secondary conidiation was observed only in treatments with $>4 \mathrm{~h}$ of wetness per day and increased with increasing wetness period within 1 day after inoculation (Table 2). Consequently, total conidial numbers were greater under continuous wetness than in any other treatment 1 day after inoculation. Total conidia then tended to decrease over time in all treatments.

Appressorial production increased with daily wetness duration at each sampling time (Fig. 2D; Table 2) and, in contrast to conidia, did not tend to decrease over the period of the experiment. Wetness duration also affected appressorial melanization (L.
F. S. Leandro, unpublished data). Melanization never occurred on appressoria formed with $4 \mathrm{~h}$ wetness and was most pronounced in treatments with $\geq 12 \mathrm{~h}$ wetness, in which $\geq 90 \%$ of appressoria became melanized.

Survival. The number of acervuli formed on leaves after freezing and incubation treatment decreased with time after transfer of plants, which had been inoculated and incubated under different intermittent wetness regimes, to the greenhouse bench (Fig. 3). There were significantly more acervuli on leaves incubated under continuous wetness than on leaves from any other treatment in both runs of the experiment (Table 3). In the first run, acervular numbers were also significantly higher in the treatment with $16 \mathrm{~h}$ wetness than in those with shorter wetness durations (Table 3). At each sampling time, the number of acervuli formed on leaves was

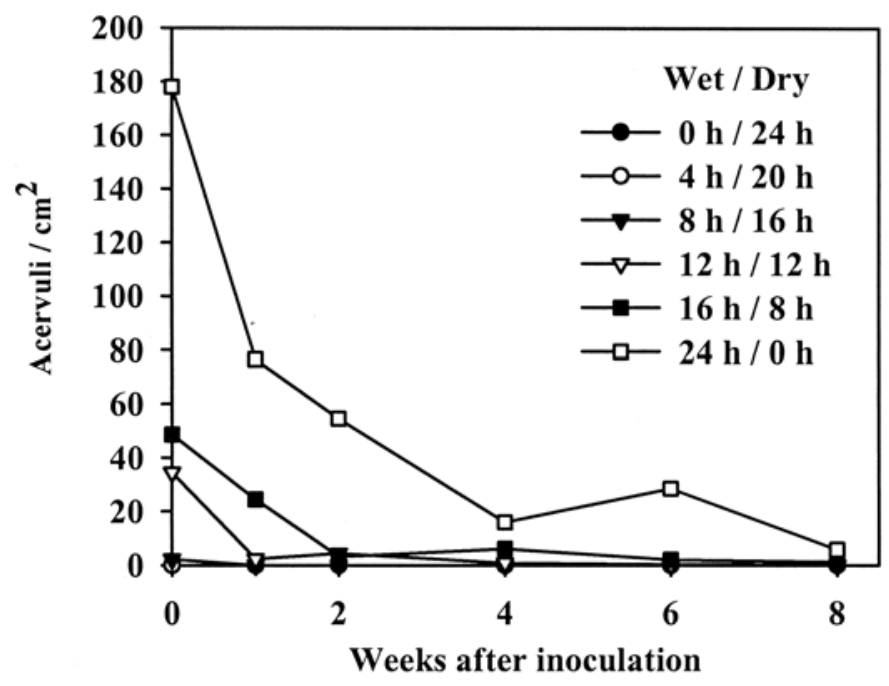

Fig. 3. Number of acervuli formed by Colletotrichum acutatum on strawberry leaves after the following treatment regime: plants were spray-inoculated with $C$. acutatum conidia, incubated at $25^{\circ} \mathrm{C}$ under six different wet/dry treatment regimes for 7 days, and maintained in the greenhouse under dry conditions for up to 8 weeks. At each sampling time during the latter period, leaf samples were excised, frozen overnight, and incubated at $25^{\circ} \mathrm{C}$ and $100 \%$ relative humidity for 1 week to induce acervular development. Data shown are for the second run of the experiment.

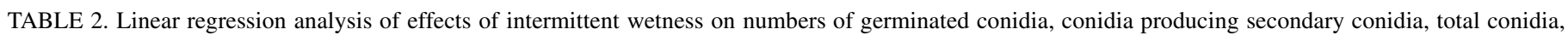

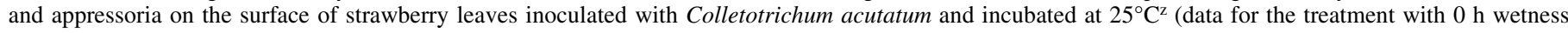
was not included in the analysis)

\begin{tabular}{|c|c|c|c|c|c|}
\hline Count & Incubation period (days) & $y$ intercept & Linear slope & $R^{2}$ & $P$ value for lack of fit \\
\hline Germinated conidia & $\begin{array}{l}1 \\
2 \\
3 \\
5 \\
7\end{array}$ & $\begin{array}{r}0.90 \\
1.69 \\
1.21 \\
1.85 \\
-0.93\end{array}$ & $\begin{array}{l}1.95 \\
1.43 \\
1.00 \\
0.40 \\
0.55\end{array}$ & $\begin{array}{l}0.75 \\
0.67 \\
0.43 \\
0.35 \\
0.43\end{array}$ & $\begin{array}{l}0.0017 * \\
0.0004 * \\
0.062 \\
0.10 \\
0.0014 *\end{array}$ \\
\hline Conidia producing secondary conidia & $\begin{array}{l}1 \\
2 \\
3 \\
5 \\
7\end{array}$ & $\begin{array}{r}-0.21 \\
-0.007 \\
0.000 \\
-0.016 \\
-0.026\end{array}$ & $\begin{array}{l}0.06 \\
0.002 \\
0.000 \\
0.002 \\
0.004\end{array}$ & $\begin{array}{l}0.41 \\
0.09 \\
- \\
0.08 \\
0.09\end{array}$ & $\begin{array}{l}0.50 \\
0.97 \\
- \\
0.47 \\
0.56\end{array}$ \\
\hline Total conidia & $\begin{array}{l}1 \\
2 \\
3 \\
5 \\
7\end{array}$ & $\begin{array}{l}34.91 \\
33.05 \\
26.68 \\
23.82 \\
13.12\end{array}$ & $\begin{array}{r}1.05 \\
0.24 \\
-0.12 \\
-0.73 \\
-0.14\end{array}$ & $\begin{array}{l}0.32 \\
0.11 \\
0.09 \\
0.31 \\
0.02\end{array}$ & $\begin{array}{l}0.0004 * \\
0.20 \\
0.0077 * \\
0.012 * \\
<0.0001 *\end{array}$ \\
\hline Appressoria & $\begin{array}{l}1 \\
2 \\
3 \\
5 \\
7\end{array}$ & $\begin{array}{l}-1.67 \\
-5.12 \\
-6.04 \\
-9.59 \\
-8.25\end{array}$ & $\begin{array}{l}2.01 \\
2.50 \\
2.46 \\
3.02 \\
2.53\end{array}$ & $\begin{array}{l}0.79 \\
0.78 \\
0.74 \\
0.82 \\
0.73\end{array}$ & $\begin{array}{l}0.024 * \\
0.60 \\
0.078 \\
0.0005^{*} \\
0.17\end{array}$ \\
\hline
\end{tabular}

$\mathrm{z} *$ indicates significant lack of fit with $P=0.05$. 
closely related $\left(r^{2} \geq 0.95\right)$ to the number of appressoria on the leaves before freezing (Fig. 4).

\section{DISCUSSION}

This study indicates that temperature and the duration of intermittent wetness periods affect germination, secondary conidiation, and appressorial development of $C$. acutatum on symptomless strawberry leaves. The optimum temperature range of 23 to $27^{\circ} \mathrm{C}$ observed for conidial germination is similar to that previously reported for germination and mycelial growth rates of $C$. acutatum in culture $(7,21,37,39)$ and for infection and sporulation on strawberry fruit $(18,39)$. Others have reported reduced or no growth of C. acutatum on agar at temperatures above $33^{\circ} \mathrm{C}(7,18,39)$ and attributed low incidence of strawberry fruit infection at $35^{\circ} \mathrm{C}$ to high pathogen mortality (39). In our study, higher incidence of conidial lysis at $35^{\circ} \mathrm{C}$ may explain the decrease in conidial populations observed on leaves under continuous wetness at this temperature. Reports on the effects of wetness duration on $C$. acutatum have been limited to studies on strawberry fruit (39) or in vitro (11). Fruit rot incidence increased with wetness duration (39), and germination on glass slides was greatly reduced when relative humidity was below $91 \%$ (11). In our study, conidial germination was also favored by increasing wetness duration, and was very low when daily wetness periods were $\leq 4 \mathrm{~h}$.

We previously reported the production of secondary conidia by C. acutatum on symptomless strawberry leaves at $26^{\circ} \mathrm{C}$ during continuous wetness (19). Induction of secondary conidiation by other fungal species has been associated with high inoculum density $(35,38)$, germination autoinhibitors $(23,38)$, nutrient limitation $(5,35,38)$, and high temperature stress $(3,38)$. Temperature and wetness effects on secondary conidiation of $C$. acutatum had not been investigated previously. In our study, secondary conidiation was observed as soon as $12 \mathrm{~h}$ after conidial germination between 20 and $30^{\circ} \mathrm{C}$, suggesting a potential for rapid inoculum increase on symptomless plants under favorable environmental conditions. The fact that most secondary conidiation was detected within $24 \mathrm{~h}$ after inoculation in both temperature and wetness experiments suggests that $C$. acutatum may lose its capacity to multiply in this manner after prolonged periods, possibly due to depletion of conidial energy reserves. The nutrient source for such multiplication is unclear, but previous studies with $C$. acutatum showed that the presence of the host was not required (19).

Appressoria serve as infection $(9,34)$ and survival $(29,32,34)$ structures in Colletotrichum spp. Appressorial development by this group of fungi is affected by several factors including nutrient stress, host surface characteristics, phylloplane microorganisms, temperature, and light intensity $(9,32)$. In our study, appressorial production was favored by cool temperatures and was severely impaired at $35^{\circ} \mathrm{C}$. Similar results have been obtained on agar,

TABLE 3. Survival of Colletotrichum acutatum on strawberry leaves incubated at $25^{\circ} \mathrm{C}$ under different wet/dry treatment regimes for 7 days and maintained under dry conditions on a greenhouse bench for up to 8 weeks; survival was then assessed by freezing the leaves overnight and incubating at $25^{\circ} \mathrm{C}$ and $100 \%$ relative humidity for 7 days to stimulate formation of $\operatorname{acervuli~}^{\mathrm{z}}$

\begin{tabular}{lcc}
\hline & \multicolumn{2}{c}{ Number of acervuli $\left(\mathrm{cm}^{-2}\right.$ leaf area $)$} \\
\cline { 2 - 3 } Treatment & Run 1 & Run 2 \\
\hline 0 h wet/24 h dry & $0.0 \mathrm{c}$ & $0.0 \mathrm{~b}$ \\
$4 \mathrm{~h}$ wet/20 h dry & $0.0 \mathrm{c}$ & $0.0 \mathrm{~b}$ \\
$8 \mathrm{~h}$ wet/16 h dry & $0.8 \mathrm{c}$ & $0.9 \mathrm{~b}$ \\
$12 \mathrm{~h} \mathrm{wet} / 12 \mathrm{~h}$ dry & $4.4 \mathrm{c}$ & $23.7 \mathrm{~b}$ \\
$16 \mathrm{~h}$ wet/8 h dry & $14.8 \mathrm{~b}$ & $62.2 \mathrm{~b}$ \\
$24 \mathrm{~h}$ wet/0 h dry & $44.8 \mathrm{a}$ & $336.6 \mathrm{a}$ \\
\hline
\end{tabular}

${ }_{\mathrm{z}}$ Values followed by the same letter within columns are not significantly $(P \geq 0.05)$ different according to Duncan's multiple range test. Values are area under the curve for acervuli formed on leaves over the survival period. where $C$. acutatum showed an optimum range for appressorial production at 20 to $25^{\circ} \mathrm{C}$ but lost the capacity to produce these structures at $30^{\circ} \mathrm{C}(21)$. As with germination and secondary conidiation, appressorial production and melanization increased with wetness duration, but in contrast to conidia, appressorial populations tended to remain stable over the course of the experiment. Appressorial melanization has been associated with protection against desiccation, UV light, unfavorable temperatures, and microbial activity $(9,29)$. Vulnerability of unmelanized appressoria to some of these factors may explain the decrease in appressorial numbers over time on leaves incubated with $8 \mathrm{~h}$ wetness per day, because a higher proportion of appressoria remained unmelanized in this treatment compared to those with longer wetness durations.

The broad temperature and wetness tolerance of appressorial production by $C$. acutatum suggests it is well adapted to survival on strawberry leaves under conditions that are suboptimal for conidial germination and multiplication. More rapid appressorial production at 23 to $26^{\circ} \mathrm{C}$ compared with other temperatures may, however, indicate that the pathogen has the ability to form survival structures even when optimum conditions for germination and secondary conidiation are present for relatively short periods.

In our study, $C$. acutatum survived for up to 8 weeks on strawberry leaves under dry greenhouse conditions. In a similar study (12), this fungus survived for over 3 months on symptomless foliage of strawberry and nonhost plants. C. acutatum was also shown to survive for up to 6 months on mummified strawberry fruit (40), 9 months in soil (7), and 2 years on pine debris (30). Survival of the fungus on strawberry and other hosts may occur as melanized appressoria $(2,30,34)$, conidia $(12,31)$, or quiescent infections (12). The strong relationship between appressoria and acervuli on leaves in our experiments suggests that $C$. acutatum survived dry conditions primarily as appressoria. Although the number of acervuli decreased rapidly over time, even the lowest acervular densities observed in our study might give rise to substantial inoculum levels because each acervulus contains many conidia.

Multiplication of $C$. acutatum on symptomless foliage prior to appearance of fruit rot or other symptoms may set the stage for epidemics that occur in strawberry production fields. Early suppression of fungal multiplication could therefore delay the onset

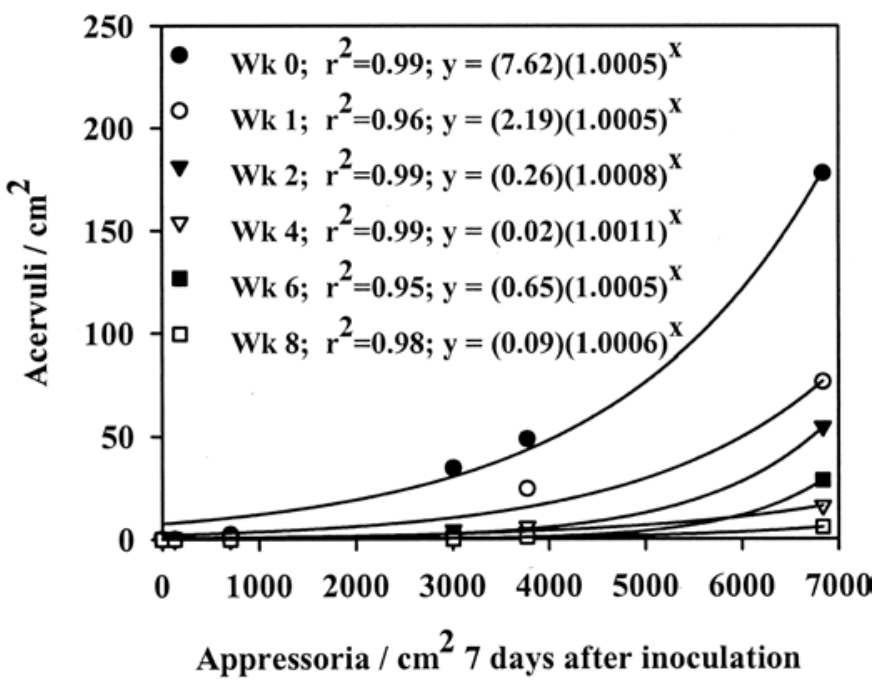

Fig. 4. Exponential relationship between the number of appressoria of $\mathrm{Col}$ letotrichum acutatum on strawberry leaves at the start of an 8-week survival period and the number of acervuli induced to form on leaves by freezing and incubating at $25^{\circ} \mathrm{C}$ and $100 \%$ relative humidity for each sampling time. During the survival period, the plants were maintained in the greenhouse under dry conditions. Appressoria were counted on leaves at the end of a 7-day incubation period at $25^{\circ} \mathrm{C}$ under six different wet/dry treatment regimes. Data shown are for the second run of the experiment. 
of epidemics and reduce disease levels. For example, reduction of C. acutatum inoculum on transplant foliage may contribute to the effectiveness of fungicide dips used in Israel to control strawberry anthracnose (14). Although most evidence for the role of symptomless foliage as a source of inoculum for strawberry anthracnose originates from controlled environment studies $(12,19)$, symptomless leaves provided sufficient inoculum to initiate fruit rot development in preliminary field trials (41). These preliminary results corroborate the relevance of our findings to the behavior of C. acutatum under field conditions.

This study provides strong evidence that $C$. acutatum can become established, persist, and produce inoculum on symptomless strawberry leaves under a range of temperatures and intermittent wetness periods. In addition to our previous work at $26^{\circ} \mathrm{C}$ under continuous wetness (19), we have now shown that secondary conidia and appressoria may be produced under environmental conditions typical of many temperate strawberry-producing areas in the world. Survival of $C$. acutatum on strawberry leaves has implications for long-distance dissemination on transplants, as well as proliferation and dissemination of the fungus within production fields. Furthermore, asymptomatic foliage of other plant species, including weeds, has been recently suggested as an additional inoculum source for $C$. acutatum (12). The environmental biology of $C$. acutatum on symptomless foliage should therefore be considered when developing management practices for strawberry anthracnose.

\section{ACKNOWLEDGMENTS}

This research was partially funded by grants from the North American Strawberry Growers Association and the Leopold Center for Sustainable Agriculture, as well as a Praxis XXI scholarship to L. F. S. Leandro from the Fundação para a Ciência e Tecnologia, Portugal. Journal Paper 19785 of the Iowa Agriculture and Home Economics Experiment Station, Ames, Iowa, Project 3564, and supported by Hatch Act and State funds. We thank R. Sakuma (Norcal, Inc.) for supplying strawberry crowns for our experiments.

\section{LITERATURE CITED}

1. Adaskaveg, J. E., and Hartin, R. J. 1997. Characterization of Colletotrichum acutatum isolates causing anthracnose of almond and peach in California. Phytopathology 87:979-987.

2. Agostini, J. P., and Timmer, L. W. 1994. Population dynamics and survival of strains of Colletotrichum gloeosporioides on citrus in Florida. Phytopathology 84:420-425.

3. Anderson, J. G., and Smith, J. E. 1971. The production of conidiophores and conidia by newly germinated conidia of Aspergillus niger (microcycle conidiation). J. Gen. Microbiol. 69:185-197.

4. Barker, I., Brewer, G., Cook, R. T. A., Crossley, S., and Freeman, S. 1994. Strawberry blackspot disease (Colletotrichum acutatum). Pages 179-182 in: Modern Assays for Plant Pathogenic Fungi: Identification, Detection and Quantification. A. Schots, F. M. Dewey, and R. P. Oliver, eds. CAB International, Wallingford, U.K.

5. Boosalis, M. G. 1962. Precocious sporulation and longevity of conidia of Helminthosporium sativum in soil. Phytopathology 52:1172-1177.

6. Dhingra, O. D., and Sinclair, J. B. 1985. Basic Plant Pathology Methods. CRC Press, Boca Raton, FL.

7. Eastburn, D. M., and Gubler, W. D. 1990. Strawberry anthracnose: Detection and survival of Colletotrichum acutatum in soil. Plant Dis. 74:161-163.

8. Eastburn, D. M., and Gubler, W. D. 1992. Effects of soil moisture and temperature on the survival of Colletotrichum acutatum. Plant Dis. 76:841-842.

9. Emmett, R. W., and Parbery, D. G. 1975. Appressoria. Annu. Rev. Phytopathol. 13:147-167.

10. European and Mediterranean Plant Protection Organization. 1994. Certification scheme: Pathogen-tested strawberry. EPPO Bull. 24:875-889.

11. Fernando, T. H. P. S., Jayasinghe, C. K., and Wijesundera, R. L. C. 1999. Factors affecting spore production, germination and viability of Colletotrichum acutatum isolates from Hevea brasiliensis. Mycol. Res. 104: 681-685.

12. Freeman, S., Horowitz, S., and Sharon, A. 2001. Pathogenic and nonpathogenic lifestyles in Colletotrichum acutatum from strawberry and other plants. Phytopathology 91:986-992.

13. Freeman, S., and Katan, T. 1997. Identification of Colletotrichum species responsible for anthracnose and root necrosis of strawberry in Israel. Phytopathology 87:516-521.

14. Freeman, S., Nizani, Y., Dotan, S., Even, S., and Sando, T. 1997. Control of Colletotrichum acutatum in strawberry under laboratory, greenhouse and field conditions. Plant Dis. 81:749-752.

15. Hartman, J. 2001. Anthracnose of greenhouse and outdoor strawberries. Kentucky Pest News 908:5-6.

16. Howard, C. M., Chandler, C. K., and Albregts, E. E. 1991. Strawberry anthracnose in Florida. Pages 219-220 in: The Strawberry into the 21st Century: Proc. North Am. Strawberry Conf., 3rd ed. A. Dale and J. Luby, eds. Timber Press, Portland, OR.

17. Howard, C. M., Maas, J. L., Chandler, C. K., and Albregts, E. E. 1992. Anthracnose of strawberry caused by the Colletotrichum complex in Florida. Plant Dis. 76:976-981.

18. King, W. T., Madden, L. V., Ellis, M. A., and Wilson, L. L. 1997. Effects of temperature on sporulation and latent period of Colletotrichum spp. infecting strawberry fruit. Plant Dis. 81:77-84.

19. Leandro, L. F. S., Gleason, M. L., Nutter, F. W., Jr., Wegulo, S. N., and Dixon, P. M. 2001. Germination and sporulation of Colletotrichum acutatum on symptomless strawberry leaves. Phytopathology 91:659-664.

20. Leandro, L. F. S., Gleason, M. L., Wegulo, S. N., and Nutter, F. W., Jr. 2001. Environmental factors affecting germination and sporulation of Colletotrichum acutatum on symptomless strawberry leaves. (Abstr.) Phytopathology 91(suppl.):S53.

21. Lee, D. H. 1993. Effect of temperature on the conidium germination and appressorium formation of Colletotrichum acutatum, C. dematium and C. gloeosporioides. (Abstr.) Korean J. Mycol. 21:224-229.

22. Legard, D. E. 2000. Colletotrichum diseases of strawberry in Florida. Pages 292-299 in: Colletotrichum: Host Specificity, Pathology and Host-Pathogen Interaction. D. Prusky, D. Freeman, and M. B. Dickman, eds. The American Phytopathological Society, St. Paul, MN.

23. Lingappa, B. T., and Lingappa, Y. 1969. Role of auto-inhibitors on mycelial growth and dimorphism of Glomerella cingulata. J. Gen. Microbiol. 56:35-45.

24. Maas, J. L., and Palm, M. E. 1997. Occurrence of anthracnose irregular leaf spot, caused by Colletotrichum acutatum, on strawberry in Maryland. Adv. Strawberry Res. 16:68-70.

25. Madden, L. V., Wilson, L. L., and Ellis, M. A. 1993. Field spread of anthracnose fruit rot of strawberry in relation to ground cover and ambient weather conditions. Plant Dis. 77:861-866.

26. Madden, L. V., Wilson, L. L., Yang, X., and Ellis, M. A. 1992. Splash dispersal of Colletotrichum acutatum and Phytophthora cactorum by short-duration simulated rains. Plant Pathol. 41:427-436.

27. Madden, L. V., Yang, X., and Wilson, L. L. 1996. Effects of rain intensity on splash dispersal of Colletotrichum acutatum. Phytopathology 86:864-874

28. Mertely, J. C., and Legard, D. E. 2000. A freezing technique to detect latent infections of Colletotrichum spp. on strawberry. (Abstr.) Phytopathology 90(suppl.):S53.

29. Muirhead, I. F. 1998. The role of appressorial dormancy in latent infection. Pages 155-167 in: Microbial Ecology of the Phylloplane. J. P. Blakeman, ed. Academic Press, New York.

30. Nair, J., Newhook, F. J., and Corbin, J. B. 1983. Survival of Colletotrichum acutatum f. sp. pinea in soil and pine debris. Trans. Br. Mycol. Soc. 81:53-63.

31. Norman, D. J., and Strandberg, O. J. 1997. Survival of Colletotrichum acutatum in soil and plant debris of leatherleaf fern. Plant Dis. 81: 1177-1180.

32. Parbery, D. G. 1981. Biology of anthracnoses on leaf surfaces. Pages 135-154 in: Microbial Ecology of the Phylloplane. J. P. Blakeman, ed. Academic Press, New York.

33. Peterson, R. A. 1977. Green leaves as a source of inoculum for anthracnose fungi, with special reference to Colletotrichum acutatum on strawberry. MS thesis. University of Queensland, Australia.

34. Prusky, D., and Plumbley, R. A. 1992. Quiescent infections of Colletotrichum in tropical and subtropical fruits. Pages 289-307 in: Colletotrichum: Biology, Pathology and Control. J. A. Bailey and M. J. Jeger, eds. CAB International, Wallingford, U.K.

35. Slade, S. J., Harris, R. F., Smith, C. S., and Andrews, J. H. 1987. Microcyclic conidiation and spore-carrying capacity of Colletotrichum gloeosporioides on solid media. Appl. Environ. Microbiol. 53:21062110.

36. Smith, B. J. 1998. Anthracnose fruit rot (black spot). Pages 31-33 in: Compendium of Strawberry Diseases. 2nd ed. J. L. Maas, ed. The American Phytopathological Society, St. Paul, MN.

37. Smith, B. J., and Black, L. L. 1990. Morphological, cultural and pathogenic variation among Colletotrichum species isolated from strawberry. Plant Dis. 74:69-76. 
38. Smith, J. E., Anderson, J. G., Deans, S. G., and Berry, D. R. 1981. Biochemistry of microcycle conidiation. Pages 329-356 in: Biology of Conidial Fungi, Vol. 2. G. T. Cole and B. Kendrick, eds. Academic Press, New York.

39. Wilson, L. L., Madden, L. V., and Ellis, M. A. 1990. Influence of temperature and wetness duration on infection of immature and mature strawberry fruit by Colletotrichum acutatum. Phytopathology 80: 111-116.

40. Wilson, L. L., Madden, L. V., and Ellis, M. A. 1992. Overwinter survival of Colletotrichum acutatum in infected strawberry fruit in Ohio. Plant
Dis. 76:948-950.

41. Wise, K. A., Leandro, L. F. S., Wegulo, S. N., and Gleason, M. L. 2002. Survival and dispersal of Colletotrichum acutatum on strawberry leaves under field conditions. (Abstr.) Phytopathology 92(suppl.):S87.

42. Yang, X., Madden, L. V., Wilson, L. L., and Ellis, M. A. 1990. Effects of surface topography and rain intensity on splash dispersal of Colletotrichum acutatum. Phytopathology 80:1115-1120.

43. Yang, X., Wilson, L. L., Madden, L. V., and Ellis, M. A. 1990. Rain splash dispersal of Colletotrichum acutatum from infected strawberry fruit. Phytopathology 80:590-595. 